\title{
The Effect of Different Ratio Bottom Ash and Fly Ash Geopolymer Brick on Mechanical Properties for Non-loading Application
}

\author{
Laila Mardiah Deraman ${ }^{1, *}$, Mohd Mustafa Al Bakri Abdullah ${ }^{2,1}$, Liew Yun Ming ${ }^{3}$, \\ Kamarudin Hussin ${ }^{2,1}$, Wan Mastura Wan Ibrahim ${ }^{1}$, and Andrei Victor Sandu ${ }^{3,1}$ \\ ${ }^{1}$ Center of Excellence Geopolymer and Green Technology (CEGeoGTech), Universiti Malaysia Perlis \\ (UniMAP), Malaysia \\ ${ }^{2}$ Faculty of Engineering Technology, Universiti Malaysia Perlis (UniMAP), Perlis, Malaysia \\ ${ }^{3}$ Gheorghe Asachi Technical University of lasi, Faculty of Materials Science and Engineering, lasi, \\ Romania
}

\begin{abstract}
This paper studies the finding of strength and water absorption of geopolymer bricks using bottom ash and fly ash as a geopolymer raw material for non-loading application with minimum strength. The study has been conducted to produce bottom ash and fly ash geopolymer bricks by varying the ratio of fly ash-to-bottom ash, solid-to-liquid and sodium silicate $\left(\mathrm{Na}_{2} \mathrm{SiO}_{3}\right)$-to-sodium hydroxide $(\mathrm{NaOH})$ in the mixing process. The compressive strength range between 3.8-4.5 $\mathrm{MPa}$ was obtained due to the minimum strength of non-loading application with $70^{\circ} \mathrm{C}$ curing temperature within 24 hours at 7 days of ageing. The optimum ratio selected of bottom ash-to-fly ash, solid-to-liquid and $\mathrm{Na}_{2} \mathrm{SiO}_{3}$-to- $\mathrm{NaOH}$ are $1: 2,2.0$ and 4.0 respectively. The water absorption result is closely related to the amount of bottom ash used in the mix design.
\end{abstract}

\section{Introduction}

The huge demand from construction industry due to the increased population has entailed the need for sustainable building materials especially bricks [1]. Production of coal power plant leads to many environmental problems. Statistic shows in Malaysia, around 18000 tons/day of coal needed by the Tanjung Bin Power Plant alone to generate electricity, as a result, large amounts of bottom ash and fly ash were produced as waste materials [2]. Hence, to overcome this problem, these waste materials will be useful when treated using geopolymerization methods to become a construction material. Bottom ash and fly ash can be utilized using inorganic polymers where it is formed by alkaline activation of aluminasilicate and alkaline solution through a polymerization process at ambient temperature to become a geopolymer because it has aluminium oxide-silicate [3]. Bottom ash and fly ash has been considered as pozzolanic materials and can be activated by using alkaline

*Corresponding author: lailamardiahderaman@gmail.com 
activation, which is acting as a binder through a chemical polymerization reaction which was known as geopolymer [4]. This paper presents the strength and water absorption of bottom ash and fly ash geopolymer bricks with a different ratio. By using the waste product also will contribute to the environmental and economic benefits $[3-5,6]$.

\section{Raw materials}

\subsection{Bottom ash}

Bottom ash was obtained from Manjung Coal-Fired Power Station, Lumut, Perak, Malaysia. The chemical composition of bottom ash where's the content of $\mathrm{SiO}_{2}$ and $\mathrm{Al}_{2} \mathrm{O}_{3}$ in the bottom ash is high which is about $43.2 \%$ and $13.7 \%$ respectively which is suitably used for geopolymer materials.

\subsection{Fly ash}

Fly ash (Class F ASTM) also obtained from Manjung Coal-Fired Power Plant, Perak Malaysia. The chemical composition of fly ash, which also contains highest Si and Al where it is suitably used for geopolymer materials.

\subsection{Alkaline Solution}

In this research, alkaline solution that was used is sodium silicate $\left(\mathrm{Na}_{2} \mathrm{SiO}_{3}\right)$ and sodium hydroxide $(\mathrm{NaOH})$. Sodium silicate is a liquid that consists $12 \%$ of $\mathrm{Na}_{2} \mathrm{O}$ and $30 \%$ of $\mathrm{SiO}_{2}$. The sodium hydroxides are originally in the form of a pellet with $98 \%$ of purity, then being diluted with distilled water (12 M) [4].

\section{Experimental method}

The mix design of geopolymer bricks is shown in Table 1. Bottom ash and fly ash were firstly weighed and mixed together properly about 2 minutes based on the mixed design. Sodium silicate and sodium hydroxide were mixing together and the mixture was stirred for 2 minutes. Then, alkaline solution was added into bottom ash and fly ash to become a geopolymer paste. The molarity of $\mathrm{NaOH}$ was fixed about $12 \mathrm{M}$ based on previous research done by Wan Mastura et al. [7] which is given the best compressive strength for geopolymer-based materials. The sized of brick are based on BS 3921: 1985 [8] where it is about $(215 \times 102.5 \times 65) \mathrm{mm}$ in work size. After a homogeneous mixture of geopolymer was obtained, it was placed into a machine that has been set following brick standard sized. The bricks were cured at temperature $70{ }^{\circ} \mathrm{C}$ for 24 hours and it was left until 7 days ageing. 
Table 1. The Mix Design of Bottom Ash and Fly Ash Geopolymer Brick.

\begin{tabular}{|c|c|c|}
\hline $\begin{array}{c}\text { Ratio of } \\
\text { Fly ash : Bottom Ash }\end{array}$ & $\begin{array}{c}\text { Ratio of } \\
\text { Solid : Liquid }\end{array}$ & $\begin{array}{c}\text { Ratio of } \\
\mathrm{Na}_{2} \mathrm{SiO}_{3}: \mathrm{NaOH}\end{array}$ \\
\hline $1: 2$ & \multirow{2}{*}{2.0} & \multirow{2}{*}{2.5} \\
\hline $1: 3$ & & \multirow{2}{*}{2.5} \\
\hline $1: 4$ & 1.5 & \multirow{2}{*}{2.5} \\
\hline \multirow{2}{*}{$1: 2$} & 2.0 & \multirow{2}{*}{2.5} \\
& 2.5 & 2.0 \\
\hline \multirow{2}{*}{$1: 2$} & \multirow{2}{*}{2.0} & 3.0 \\
\hline
\end{tabular}

\subsection{Testing}

The strength of bottom ash and fly ash geopolymer brick was evaluated using compressive strength test. Compressive strength is tested by imposing the bricks to compression load until failure. The compressive strength tested based on ASTM C67-11 by using hydraulic Compressive Testing Machine VU 2000 at the load speed rate $0.6 \mathrm{~N} / \mathrm{mm}^{2} / \mathrm{s}$ [9]. The effects of the compressive strength of geopolymer brick were only tested on their stretcher face area [7-9].The maximum load was recorded and the strength calculated by dividing the maximum load by the area of the surface subject to loading. In this research, three samples are tested at each ratio to evaluate the strength due to the non-loading application. The strength was recorded in $\mathrm{N} / \mathrm{mm}^{2}$ to the nearest $0.1 \mathrm{~N} / \mathrm{mm}^{2}$. Water absorption test was carried out based on ASTM C140 [10] for every age of curing specimens. Test specimen immersed in water at temperature 15 to $27{ }^{\circ} \mathrm{C}$ for 24 hours. After 24 hours, the specimens are removed and weighted and recorded as $W_{s}$ (saturated weight). Then, the sample is dried in the oven at $110{ }^{\circ} \mathrm{C}$ for not less than 24 hours or until two successive weight at intervals of 2 hours show an increment of loss not greater than $0.2 \%$ of the last previous determined weight of the specimen. The weights of dried specimen are recorded as $W_{d}$ (oven-dry weight).

\section{Results and discussion}

Fig. 1 shows the compressive strength of ratio fly ash-to-bottom ash. From the data obtained, ratio 1:2 showed a compressive strength of $4.5 \mathrm{MPa}$ which has reached the minimum strength for non-load bearing based on ASTM C129-11. The compressive strength of geopolymer bricks was decreased as the ratio of fly ash to bottom ash increased. Since bottom ash is not fineness and do not have a high surface area, it couldn't dissolve more silica and alumina thus can lead to the low compressive strength according to the properties. 


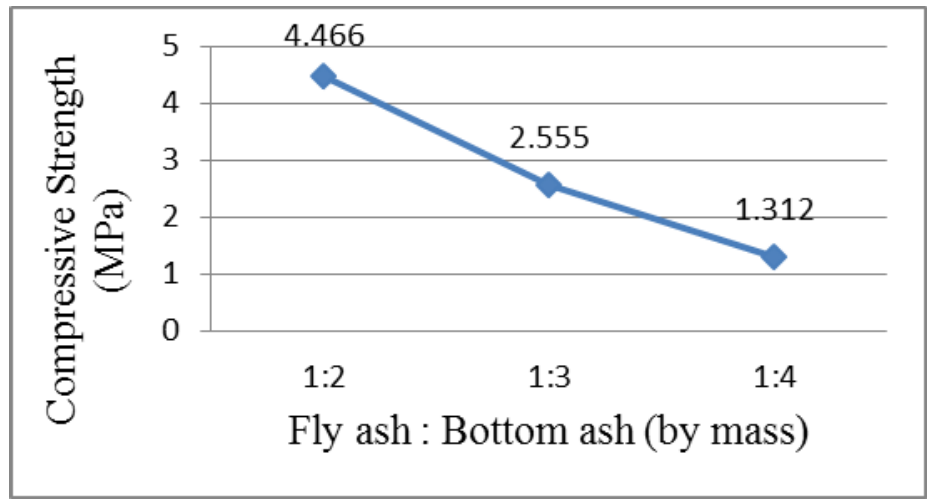

Fig. 1. The compressive strength of fly ash-to-bottom ash ratio.

Fig. 2 shows the water absorption of geopolymer brick. Ratio 1:2 showed the lowest readings of water absorption which is $4.3 \%$ of water absorption, while the ratio of $1: 3$ and $1: 4$ are $4.4 \%$ and $4.5 \%$ respectively. The higher ratio showed more bottom ash used in the designed mixture. More bottom ash used leads to the higher percentage of water absorption. Since the properties of bottom ash are porous and irregular surface than fly ash which allows it to behave like a water reservoir that retains water, so, the percentage of water absorption is higher.

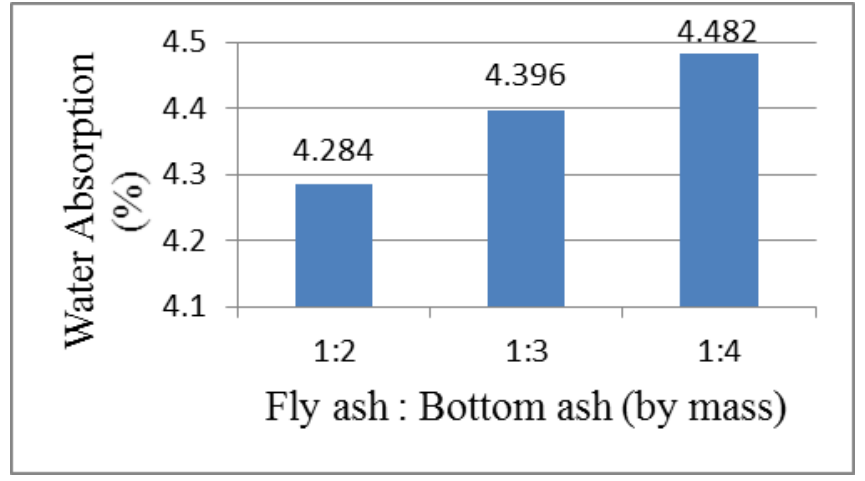

Fig. 2. The water absorption of fly ash to bottom ash ratio.

The compressive strength for effect solid-to-liquid ratio is shown in Fig. 3. After obtaining the optimum value compressive strength of fly ash to the bottom ratio (1:2), then the experiment continues with finding the optimum ratio of solid-to-liquid. Three ratios are selected based on the trial and error that has been done by other researchers which are 1.5, 2.0 and $2.5[3,7,11]$. At a ratio of 2.0 , compressive strength showed $4.44 \mathrm{MPa}$ where it is acceptable for minimum strength for the non-load bearing application. Highest compressive strength shows more fly ash used. 


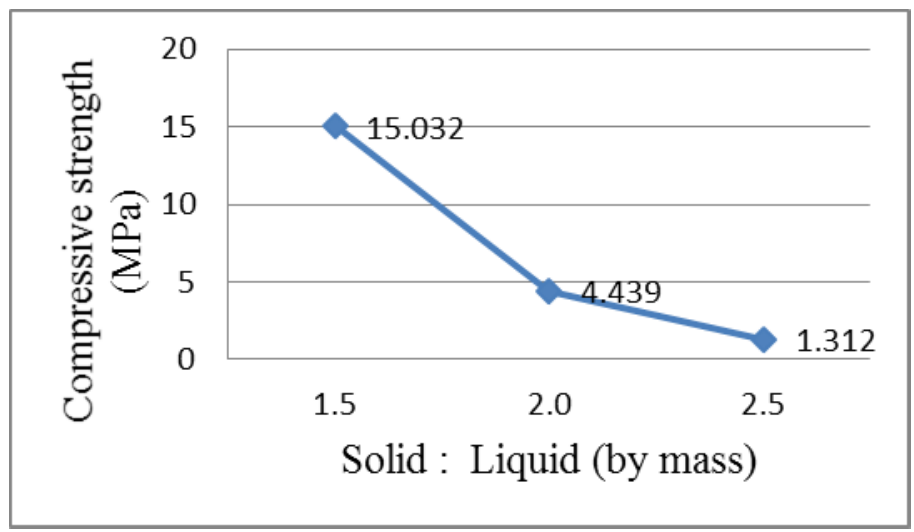

Fig. 3. The compressive strength of solid-to-liquid ratio.

Water absorption results with three different ratios of solid-to-liquid shown in Fig. 4. The lowest percentage resulting in solid-to-liquid 2.0 with value $5.18 \%$. Then, for solid-toliquid ratio, 2.5 have the highest water absorption which is $6.96 \%$ and the ratio of 1.5 has a value $5.16 \%$. The higher percentage of water absorption indicates to not fully reacted precursor with alkaline activator causing water retained in the pores especially in bottom ash because physical properties of bottom ash are porous and less pozzolanic.

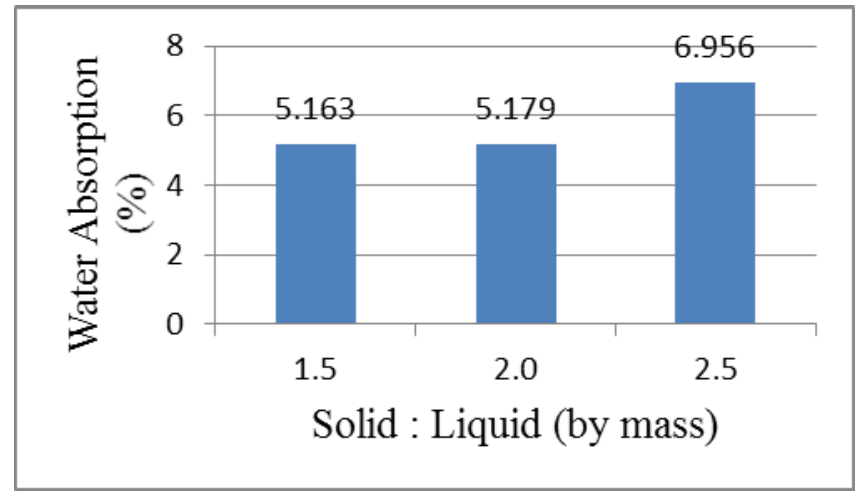

Fig. 4. The water absorption of solid to liquid ratio.

Experiments continue with finding the optimum ratio for sodium silicate $\left(\mathrm{Na}_{2} \mathrm{SiO}_{3}\right)$-tosodium hydroxide $(\mathrm{NaOH})$. Fig. 5 shows the graph results of ratio $\mathrm{Na}_{2} \mathrm{SiO}_{3}$-to- $\mathrm{NaOH}$. The minimum compressive strength for non-load bearing indicates at a ratio of 4.0 which are 3.84 MPa. Then, the ratio of 2.0 and 3.0 has a value of $6.405 \mathrm{MPa}$ and $6.19 \mathrm{MPa}$ respectively. According to Zarina et al. (2015), when the $\mathrm{Na}_{2} \mathrm{SiO}_{3}$-to- $\mathrm{NaOH}$ ratio was more than 3.0 the compressive strength tends to decrease that may due to excessive alkali content which retarded the geopolymerization process. It occurred when $\mathrm{Si}-\mathrm{Al}$ phase [12]. 


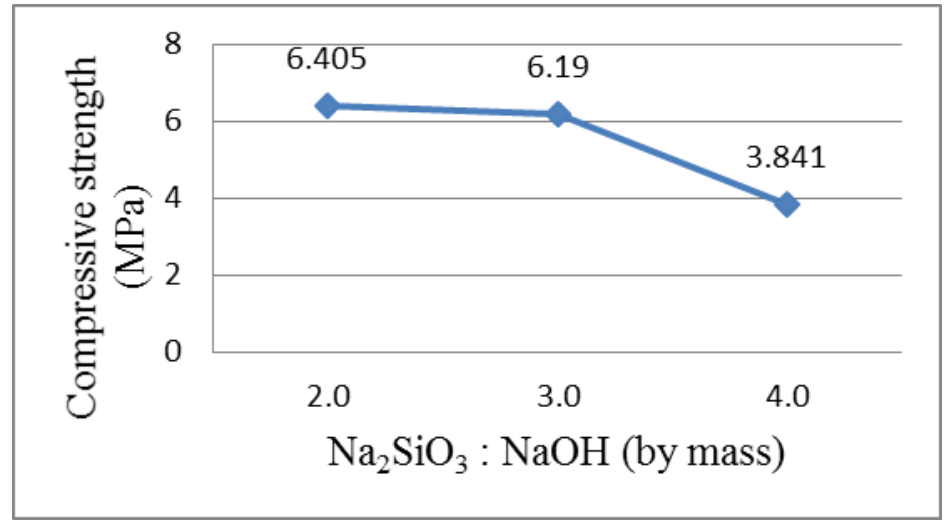

Fig. 5. The compressive strength of $\mathrm{Na}_{2} \mathrm{SiO}_{3}$-to- $\mathrm{NaOH}$ ratio.

Fig. 6 shows the graph percentage of water absorption with different $\mathrm{Na}_{2} \mathrm{SiO}_{3}$-to- $\mathrm{NaOH}$ ratios. The results show the lowest percentages of water absorption are obtained at 4.0 ratios which are $3.21 \%$. The highest percentage of water absorption shows at 3.0 ratio which is $5.85 \%$ while ratio 2.0 calculated $5.30 \%$ of water absorption. The pores in the geopolymer bricks may affect the absorption of water. Lower compressive strength shows lower in the absorption of water.

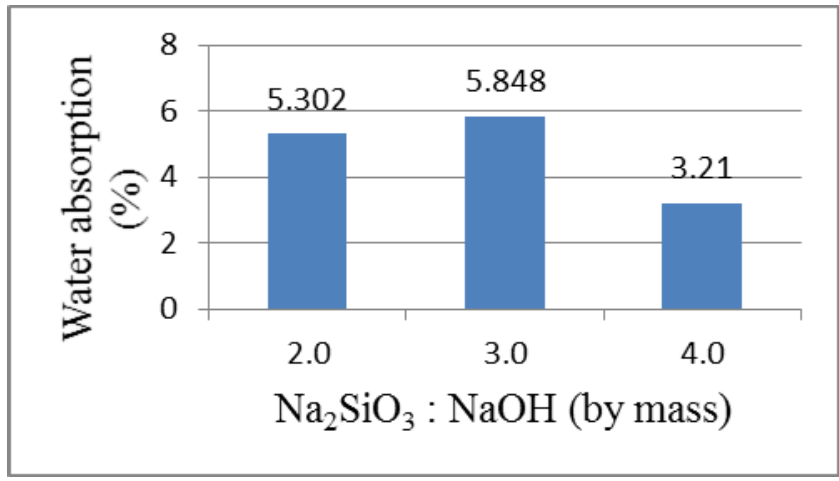

Fig. 6. The water absorption of $\mathrm{Na}_{2} \mathrm{SiO}_{3}$ to $\mathrm{NaOH}$ ratio.

\section{Conclusion}

According to the analysis of compressive strength results of bottom ash and fly ash geopolymer brick, the strength will increase with the increasing of fly ash. This may due to the size particle of fly ash, which is very fine and act like an ordinary Portland cement. The optimum ratio for bottom ash-to-fly ash, solid-to-liquid and $\mathrm{Na}_{2} \mathrm{SiO}_{3}$-to- $\mathrm{NaOH}$ ratio are 1:2, 2.0 and 4.0 respectively. The maximized used of bottom ash, the minimum strength for the non-load bearing is selected since it is not as widely used compared with fly ash or other geopolymer material. More bottom ash used will result higher percentage of water absorption due to the more surface area found and the pozzolanic of bottom ash also can retain water.

This study was supported by Center of Excellence Geopolymer and Green Technology $(\mathrm{CEGeoGTECH})$ UniMAP and School of Materials Engineering, UniMAP. 


\section{References}

1. J.M. Bennet, M. Sudhakar, C. Natarajan, European International Journal of Science and Technology, 2 (2013)

2. A. Muhardi, M. Aminaton, K.K. Kassim, M.A. Mahir, Electron J. Geotech. Eng., 15 (2010)

3. Y. Zarina, A.M. Mustafa Al Bakri, H. Kamaruddin, I. Khairul Nizar, A.R. Rafiza, Advance Material Science, 34 (2013)

4. J.C. Swanepoel, C.A. Strydom, Appl. Geochem., 17 (2002)

5. M.T. Muhammad Fahem, A.M. Mustafa Al Bakri, C.M. Ruzaidi, H. Kamaruddin, A.M. Izzat, A. Alida, Engineering Materials, 594 (2014)

6. K.S. Gan, P.C. Chui, CV978 Report, School of Civil and Environmental Engineering, Nanyang Technological University, Singapore (2003)

7. W.I Wan Mastura, A.M. Mustafa Al Bakri, A.V. Sandhu, H. Kamaruddin, I.G. Sandu, I. Khairul Nizar, A.K. Aeslina, M. Bnhussain, Rev. Chim.-Bucharest, 65 (2014)

8. BS 3921 - Spesifications of Clay Bricks, (1985)

9. American Society for Testing and Material, ASTM C67-11 (2011)

10. American Society for Testing and Material, ASTM C140-12 (2011)

11. A.M. Mustafa Al Bakri, H. Kamarudin, M. Bnhussain, I. Khairul Nizar, A.R Rafiza, Y. Zarina, J. Eng. Technol. Res., 3 (2011)

12. Y. Zarina, A.M. Mustafa Al Bakri, H. Kamarudin, I. Khairul, R. Rafiza, S. Andrei, Materials, 8 (2015) 